\title{
Equatorial counter electrojets and polar stratospheric sudden warmings - a classical example of high latitude-low latitude coupling?
}

\author{
C. Vineeth ${ }^{1}$, T. Kumar Pant ${ }^{2}$, and R. Sridharan ${ }^{2}$ \\ ${ }^{1}$ SRI International, Menlo Park, CA, USA \\ ${ }^{2}$ Space Physics Laboratory, Vikram Sarabhai Space Centre, Trivandrum, India
}

Received: 1 April 2009 - Revised: 28 July 2009 - Accepted: 5 August 2009 - Published: 12 August 2009

\begin{abstract}
Favored occurrences of Equatorial Counter Electrojets (CEJs) with a quasi 16-day periodicity over Trivandrum $\left(8.5^{\circ} \mathrm{N}, 76.5^{\circ} \mathrm{E}, 0.5^{\circ} \mathrm{N}\right.$ diplat.) in association with the polar Stratospheric Sudden Warming (SSW) events are presented. It is observed that, the stratospheric temperature at $\sim 30 \mathrm{~km}$ over Trivandrum shows a sudden cooling prior to the SSWs and the CEJs of maximum intensity which occurs around this time. In general stronger CEJs are associated with more intense SSW events. The stratospheric zonal mean zonal wind over Trivandrum also exhibits a distinctly different pattern during the SSW period. These circulation changes are proposed to be conducive for the upward propagation of the lower atmospheric waves over the equatorial latitudes. The interaction of such waves with the tidal components at the upper mesosphere and its subsequent modification are suggested to be responsible for the occurrence of CEJs having planetary wave periods.
\end{abstract}

Keywords. Ionosphere (Equatorial ionosphere; Ionosphereatmosphere interactions; Wave propagation)

\section{Introduction}

The equatorial electrojet (EEJ) is an intense band of eastward current system that flows, during daylight hours, along the dip equator at an altitude centered at around $105 \mathrm{~km}$. It is known that the quiet day geomagnetic variations are driven by the tidal winds in the dynamo region. The changes in the lower thermospheric wind system overhead can be related or correlated with changes in the quiet day geomagnetic variations (Hysell et al., 2002). However, a relationship between high latitude zonal wind and the equatorial electrojet has also

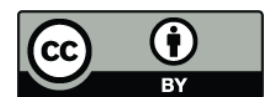

Correspondence to: C. Vineeth (cnvins@gmail.com) been shown by Stening et al. (1996). Apart from these, clearcut signatures of the planetary wave (PW) oscillation have also been reported in the EEJ, through independent studies over the globe (Parish et al., 1994; Abdu et al., 2006; Vineeth et al., 2007a).

The reversal of the EEJ during the afternoon hours on geomagnetically quiet days called as the "Counter Electrojets (CEJs)" has remained as a challenge warranting an exclusive explanation since it was identified by Gouin and Mayaud (1967). Though many theories have been proposed for the reversal of the EEJ currents, the exact causative mechanism still remains unexplainable. The local effect within the EEJ region such as gravity wave associated vertical winds (Raghavarao and Anandarao, 1980; Aanadarao and Raghavarao, 1987) and the changes in the tidal components (Somayajulu et al., 1993) are some of the earlier suggestions for CEJs. On the other hand, contributions of the global wind and current systems to the occurrence of CEJs have also been brought out (Stening et al., 1996; Gurubaran et al., 2002). The relation of CEJ occurrence with the prevailing phase of Stratospheric Quasi Biennial Oscillation (SQBO) has been indicated by Chen et al. (1995). Further, in a study dealing with the occurrence of CEJ during the winter months Stening et al. (1996) have suggested an association of Stratospheric Sudden Warming (SSW) for the occurrence of CEJ events. In a recent study, Chau et al. (2009) have reported a distinctive pattern in the equatorial daytime $\boldsymbol{E} \times \boldsymbol{B}$ drift during the SSW years.

Recently Vineeth et al. (2007b) have shown that the CEJs were associated with a cooling in the equatorial mesopause. The Gravity Wave (GW) associated vertical wind and the modifications of the tidal components were proposed for this observation. Similarly, the occurrence of CEJs of quasi 16-day periodicity has also been shown during the winter months of the SSW year 2006 (Vineeth et al., 2007a). It was shown that the quasi 16-day wave modulated the tidal components and whenever the amplitude of the tidal components

Published by Copernicus Publications on behalf of the European Geosciences Union. 


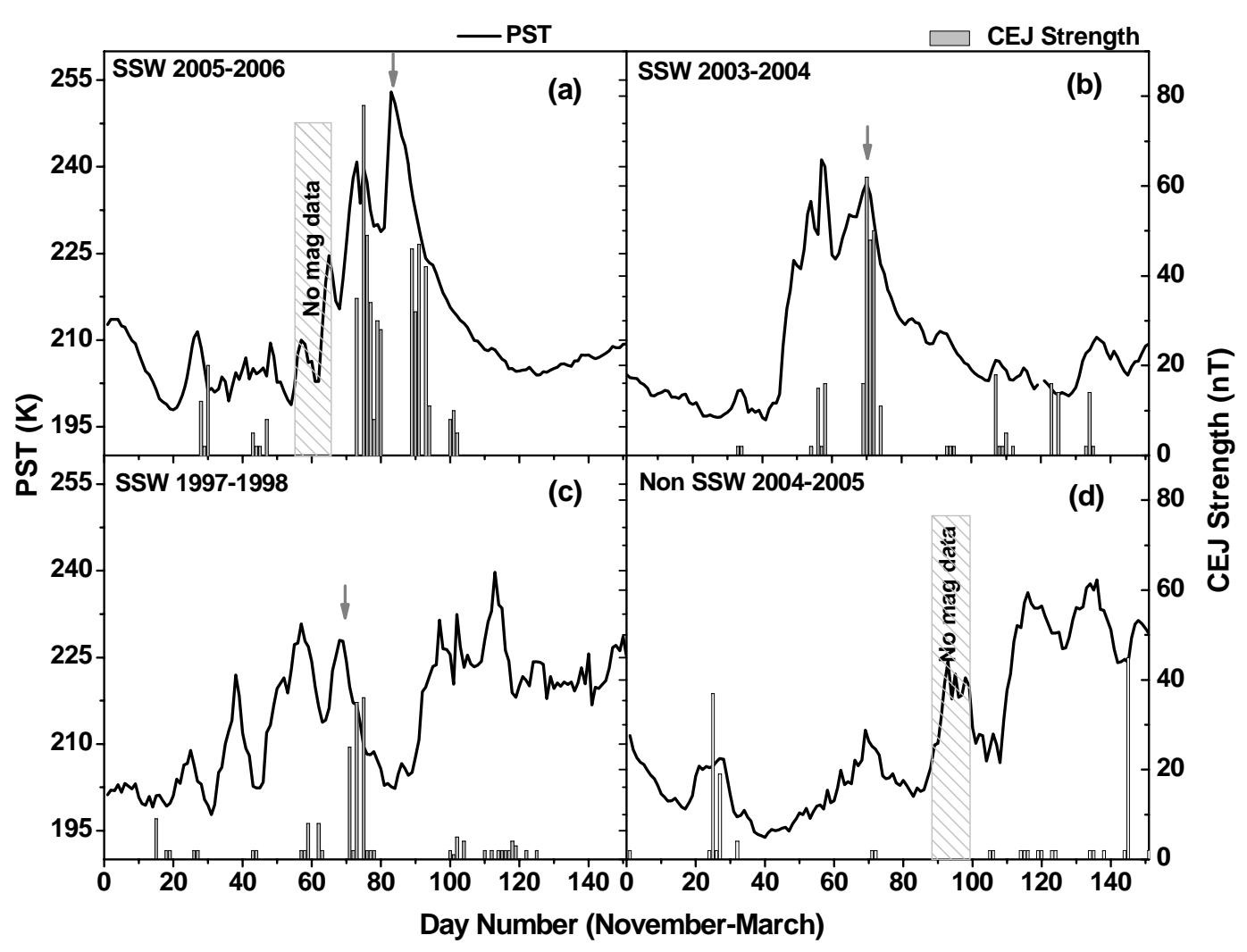

Fig. 1. Daily variation (1 November-31 March) of polar stratospheric temperature (at $10 \mathrm{hPa}$ ) and the CEJ strength during the SSW years (a) (2005-2006), (b) (2003-2004) (c) (1997-1998) and a non-SSW year (d) (2004-2005). The central date of the major SSW is marked in each plot using vertical arrows.

minimized, CEJ occurred. However, the data presented earlier could only indicate a plausible connection between the SSW and the occurrence of CEJ rather than establishing a direct connection between the two. It has been realized from the aforesaid studies that there may not be one single cause for the occurrence of CEJ. Logically one could anticipate the periodic/episodic occurrence of CEJ could be an outcome of large-scale/global-scale processes and the isolated/sporadic events could be due to local processes. Further analysis of additional data clearly brings out that periodic occurrence of CEJ and the global circulation patterns at stratospheric altitudes are intimately connected during the SSW years. This paper aims at reporting some preliminary results pertaining to the above.

\section{Database}

The EEJ induced magnetic field at the surface was measured using a Proton Precession Magnetometer (PPM) from Trivandrum $\left(8.5^{\circ} \mathrm{N}, 76.5^{\circ} \mathrm{E}, 0.5^{\circ} \mathrm{N}\right.$ diplat. $)$, a geomagnetic dip equatorial station in India. Though a PPM gives only the total field, the magnetic field component is essentially horizontal over the dip equator. The diurnal variation of the mag- netic field during winter months (November-March) were visually scanned through and occurrences of geomagnetically quiet afternoon CEJs were separated out for three major mid winter SSW years (2005-2006), (2003-2004) and the (19971998). The former two cases represent the SSWs occurred in eastward phase of equatorial QBO and the latter westward. The CEJ occurrence during a normal (i.e. non SSW) year (2004-2005) was also examined for comparison. The global stratospheric wind and temperature data for the corresponding periods were obtained from NCEP/NCAR reanalysis data (Kalnay et al., 1996).

\section{Observations}

The time variation of the zonal mean Polar Stratospheric Temperature (PST) and the strength of the afternoon CEJs observed during November-March period for three SSW years (2005-2006, 2003-2004 and 1997-1998) and a non SSW year (2004-2005) are depicted in Fig. 1. It is very well evident from the figure that, the CEJs occurred more frequently during the SSW years and its occurrence was more or less simultaneous with the warming observed in PST. Moreover, the occurrence of a group of CEJs during the three SSW 
years exhibited a quasi periodicity of 16-days. During the non SSW year the CEJ occurs more or less sporadically with lesser strength than that occurs during the SSW years.

Figure 1a depicts the PST and CEJ strength during a strong SSW that ( 43 K) occurred on 22 January 2006 (day number 83 in Fig. 1a). Two minor warmings also could be noticed around day number 66 and 71 during this year. Three episodes of CEJs were observed over Trivandrum during this period. The first set of CEJs occurred around day numbers 74-79, which seems to be associated with the minor warming in the PST. The strongest CEJ indicated a field reversal of $\sim 78 \mathrm{nT}$ around day number 75 . The consecutive CEJs exhibited less intensity than this. A second episode of CEJs occurred around day numbers 89-92, and the strength of the strongest CEJ in this set seen through the field reversal was found to be $\sim 47 \mathrm{nT}$. It must be mentioned that, the PST exhibited maximum warming during this period. The third episode of CEJs occurred around day numbers 101103. The strength of the CEJ was found to be significantly less $(\sim 10 \mathrm{nT})$ during the third episode, compared to the other earlier episodes.

Figure $1 \mathrm{~b}$ shows the time variation of PST and strength of the CEJ during the SSW year of (2003-2004). The PST enhancement during the major warming was $\sim 27 \mathrm{~K}$ and occurred at around day number 70 . There were also three sets of CEJs observed during this SSW year. It is well evident from the figure that the CEJs were closely related to the sudden warmings over the polar region. The first set occurred between day numbers 54 and 59 and the second between 69 and 74. The third sets of CEJs were observed between day numbers 89 and 91 . Figure 1c represents yet another SSW year of (1997-1998). The intensity of the SSW (occurred around day number 70) was less compared to the other two SSWs (zonal wind reversal was also nominal). The CEJs of occurrence periodicity of quasi 16-day were observed in this year too. But the strengths of the CEJs were much less compared to the other SSW years. The extent of warming in the PST was also observed to be less during this year. The noteworthy observation is that in the year (1997-1998), unlike the other two cases, the PST didn't come to normal level after the warming. A second episode of minor warming was observed around day number 100, after the major warming. Interestingly partial CEJs were observed corresponding to the minor warming also. It is very well evident from Fig. 1a, b, and $c$ that the episodic and significantly intense CEJs occur during the SSW period.

Figure 1d depicts the PST and strength of the CEJs observed during a non-SSW year (2004-2005). It is clear that there was no periodicity in the occurrences of CEJs during this year. In fact, only three fully developed CEJs were observed during the considered period of study in the non-SSW year, while all others were only partial CEJs.

It is very well known that during the SSW years the global circulation exhibits significant variations (Dunkerton, 1981). The global wind changes significantly influence the occur- rence of CEJs as reported earlier (Chen et al., 1995; Stening et al., 1996; Gurubaran et al., 2002). It is also realized that, the prevailing wind in the lower atmosphere has a major role in filtering out the upward propagating waves and tides (Hagan et al., 1999). In this context, the changes in the global wind pattern at stratospheric altitudes have been looked into, and Fig. 2 depicts the latitudinal variation of the zonal mean zonal wind at $10 \mathrm{hPa}(\sim 30 \mathrm{~km})$, obtained from NCEP/NCAR reanalysis data for the considered SSW years and the normal year. It is clear from the figure that the wind during the SSW years showed a markedly unusual pattern. The zonal-mean zonal wind over the equator during the SSW years (2005-2006 and 2003-2004) was eastward and during the SSW year (1997-1998) and non-SSW year (2004-2005) westward in association with the stratospheric Quasi Biennial Oscillation (SQBO). In addition to this, during the SSW years, the zonal-mean zonal wind showed a channel of deceleration (arrows on Fig. 2a, b, and c), which first appeared over equatorial region and later on progressed towards the North Pole. The appearance of this pattern (zero wind channel) has been found to be pronounced during the SSW years (Fig. 2a and b), whereas during the normal year (Fig. 2d) no such formation of the wind deceleration at near equatorial region has been seen.

Apart from this, a sudden cooling, followed by a rapid recovery in Stratospheric Temperature (ST) (at $10 \mathrm{hPa}$ ), has been observed over Trivandrum during the SSW years (Fig. 3). The ST obtained from the NCEP/NCAR reanalysis data showed a cooling of $\sim 8 \mathrm{~K}$ from the mean temperature level (shown in dashed line in Fig. 3a) during the SSW (2005-2006) at around day number 73, preceding by 9 days the major warming, which occurred on day number 83 by 9 days. During the SSW (2003-2004), the ST showed a cooling of $\sim 5 \mathrm{~K}$ around day number 60 , which also preceded the major warming by 9 days. Similarly, the ST during the SSW (1997-1998) exhibited a cooling by $3.5 \mathrm{~K}$ around day number 62 which preceded the major SSW by 8 days. The ST recovered to the mean level after the major SSW and dropped $(\sim 4.5 \mathrm{~K})$ once again around day number 95 about 5 days prior to the minor SSW occurred around day number 100 . Further, it should be noted that the major CEJ events were seen to occur a few days after the ST cooling prior to the major SSW. The central dates of the major SSW in all the years have been marked by arrows in the figures. During the non-SSW year the ST didn't exhibit a sudden cooling and immediate recovery rather showed a gradual cooling with a very slow recovery.

\section{Results and discussions}

Various possible mechanisms for the reversal of the EEJ current have been suggested in the past, as mentioned earlier. For example the CEJ may be produced by the westward current, driven by the lunar semidiurnal tide (Rastogi, 1974), or 

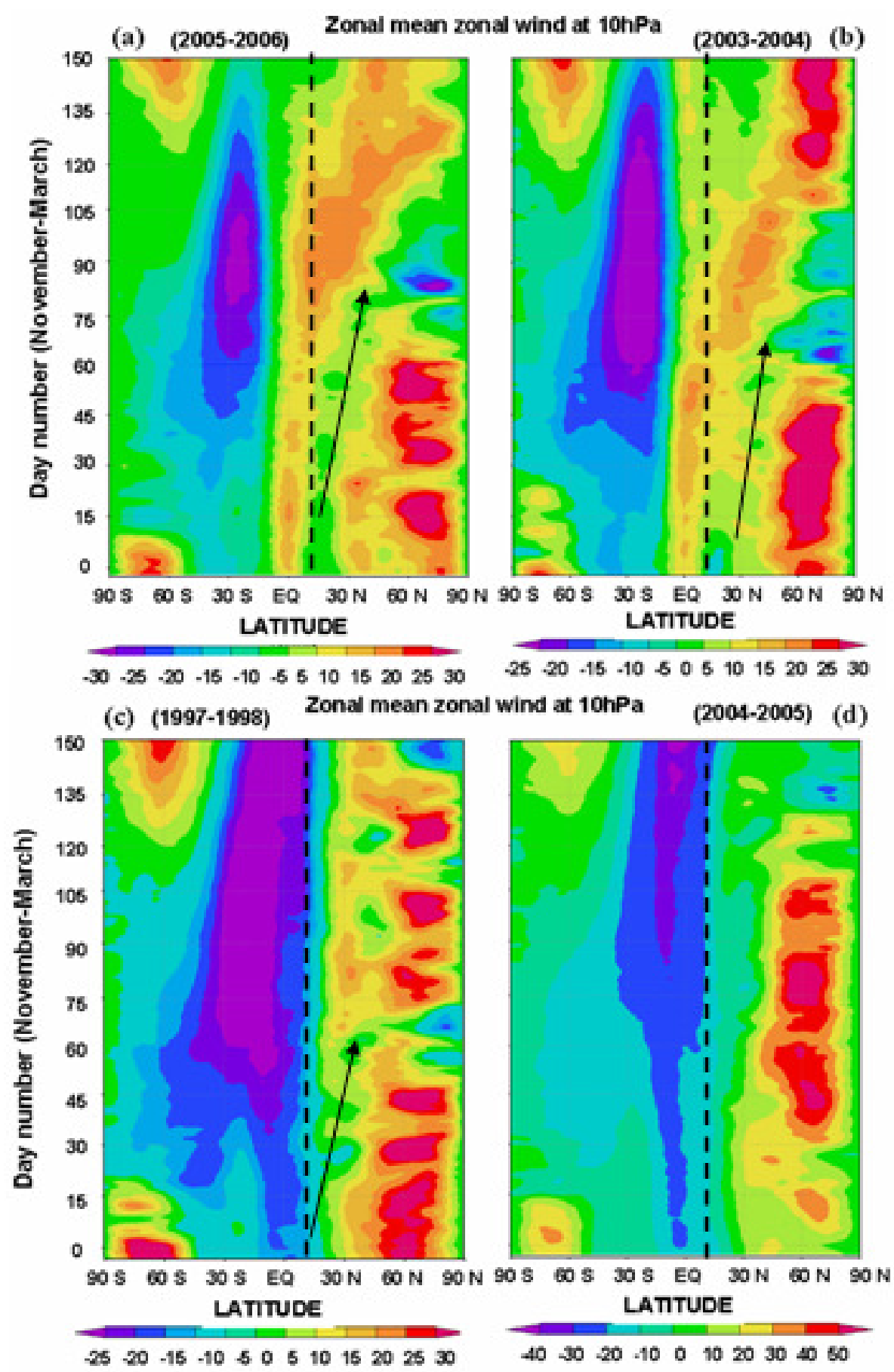

Fig. 2. The zonal mean zonal wind around the globe during the period 1 November-31 March, for the SSW years (a) (2005-2006), (b) (20032004), (c) (1997-1998) and a non-SSW year (d) (2004-2005). The location of Trivandrum is shown using dotted lines and zero wind line is marked using arrows. Positive wind is eastward.

by the local upward wind of $15-20 \mathrm{~m} / \mathrm{s}$ of gravity wave origin (Raghavarao and Anandarao, 1980). Another mechanism that has been proposed involves additional currents at $110 \mathrm{~km}$ over and above the normal eastward $S_{q}$ current, which is confined at the geomagnetic equator at $105 \mathrm{~km}$. This additional current could flow either eastward or westward. When it is westward and sufficiently intense then it would manifest as CEJ (Rastogi et al., 1992). On the other hand, Stening et al. (1996) and Gurubaran et al. (2002) showed that, the CEJ could be a part of the global wind change in the dynamo 


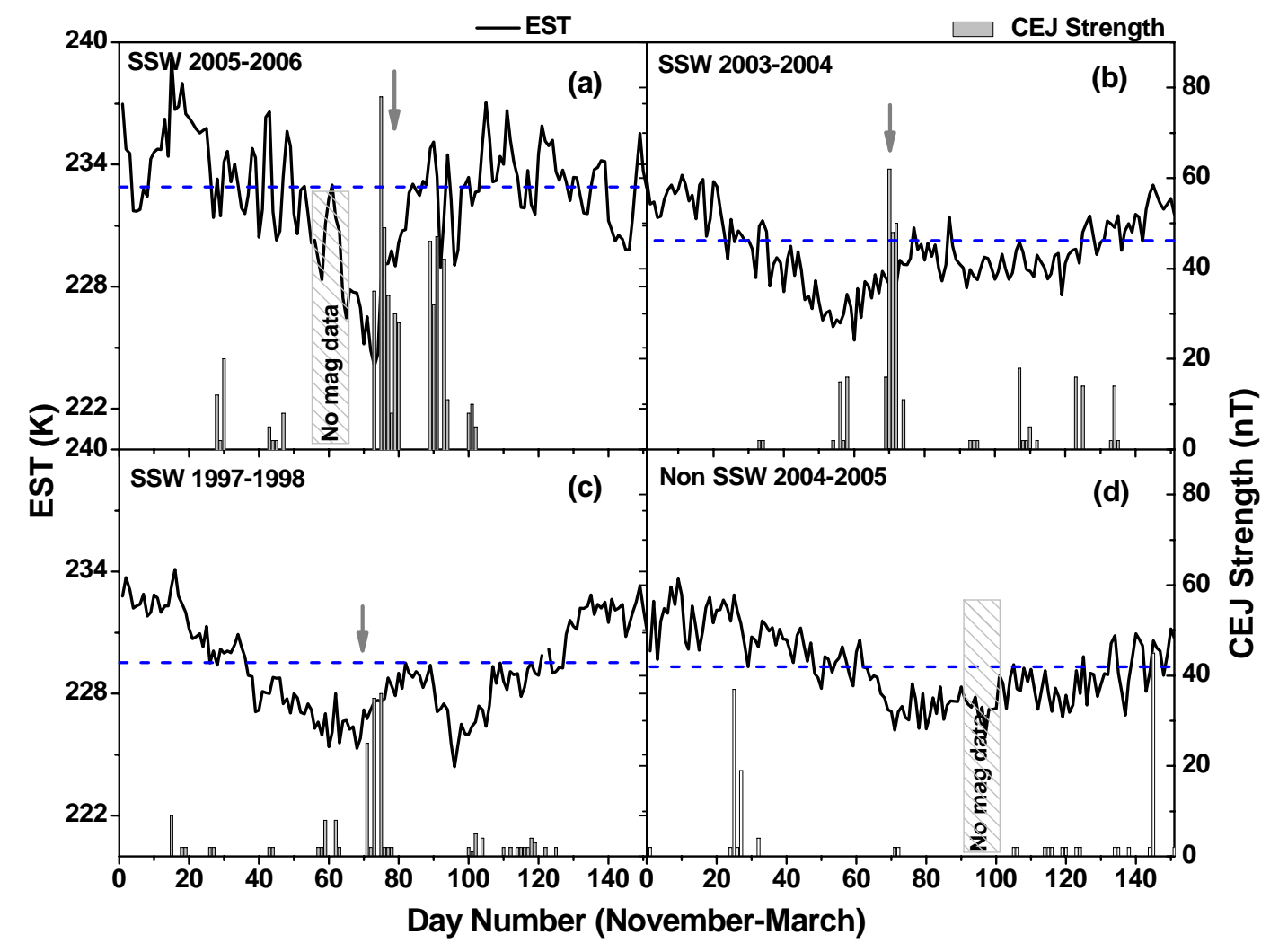

Fig. 3. Daily variation of stratospheric temperature (at $10 \mathrm{hPa}$ ) over Trivandrum and the CEJ strength during the SSW years (a) (2005-2006), (b) (2003-2004), (c) (1997-1998) and a non-SSW year (d) (2004-2005). The central date of the major SSW is marked in each plot using vertical arrows.

region. In a modeling study dealing with the stratwarm effect on lunar tide, Stening et al. (1997) showed that the tidal amplitudes were significantly affected when the SSW effect was included in the model. Further association of the phase of the Quasi Biennial Oscillation (QBO) was also found to have important bearing on the occurrence of CEJ (Chen et al., 1995). When compared with the QBO wind phase in the stratosphere, the occurrence of the CEJ found to increase during the eastward phase of the $\mathrm{QBO}$ and to decrease during the westward phase. This relationship suggested a possible mechanism for the occurrence of the CEJ. Under certain conditions, the interaction between the upward propagating planetary waves and the solar or lunar semidiurnal tides could increase the amplitude and also cause changes in phase, ultimately resulting in the occurrence of the CEJ thus indicating the importance of lower atmospheric dynamics for the generation of the CEJ.

The occurrence of QBO is suggested to be due to the interannual variability of either wave excitation mechanisms or background winds through which they propagate. The stratospheric QBO winds selectively control the upward propagation of those waves that have their origin in the lower atmosphere depending on their phase velocity (Hagan et al., 1999). In this context, it could be appreciated that the changes in the stratospheric circulation significantly influence not only the middle atmosphere energetics/dynamics but also the upper atmospheric electrodynamics. This is possible due to the filtering of the waves and tides, as they propagate upwards and essentially would depend on the background wind conditions. The effect of the mean wind is crucial for the internal gravity waves and planetary waves originating in the troposphere. Winds in the troposphere and stratosphere strictly limit the phase speeds of the waves capable of reaching at upper mesospheric altitudes. The changes in the mean zonal flow accompanying seasonal changes, SSWs etc., would therefore dramatically alter the nature of the waves in the mesosphere (Lindzen, 1981).

In the light of the above, the occurrence of CEJs during the SSW year is also proposed to be due to the selective permeability of the stratospheric background wind during the SSW year. As is seen from Fig. 2, the zonal-mean zonal wind at stratospheric altitude exhibited significant changes during the SSW years. The winds over equator were predominantly eastward during the SSW years of 2005-2006 and 20032004 and westward during the SSW year (1997-1998) and non-SSW year (2004-2005) in association with the SQBO. Apart from this, the zonal-mean zonal wind also showed a strong deceleration (zero wind condition), appearing first 
over equator and later on progressed towards the North Pole during the SSW years. As has been mentioned earlier, during the non-SSW year no clear-cut formation of the zonal-mean zonal wind deceleration occurred over near-equatorial latitudes.

It is proposed that, the zero wind condition seen at stratospheric level during the SSW years would allow the westward propagating gravity waves and planetary waves (such as the quasi 16-day wave) to propagate upward as discussed (Liu and Roble, 2002). Similarly, the prevailing wind at mesospheric altitude also plays an important role in the propagation of these waves further. The appearance of the stratospheric zero wind line over equatorial latitude is believed to be due to the pre-conditioning associated with the SSW. The meridional circulation associated with sudden warming can induce upwelling in the equatorial region and produce a cooling in the equatorial lower stratosphere while modifying the distribution of minor constituents (Randel et al., 2002). The sudden cooling in stratospheric temperature over Trivandrum (Fig. 3) during the SSW years is believed to be associated with this upwelling. It must be mentioned that, the CEJs of maximum strength were observed some time after this sudden stratospheric cooling over the tropics. The mesospheric wind is also expected to exhibit changes in association with this stratospheric dynamic/energetics changes. It is suggested that, the background circulation changes observed during the SSW periods allow the westward propagating PWs to reach over upper mesospheric altitudes unlike in the normal years. Recent studies of Chau et al. (2009) and Goncharenko and Zhang (2008), which show the ionospheric response of the SSW over the equator and mid latitudes respectively, supports this argument.

The PWs at upper mesospheric heights are capable of interacting nonlinearly with the tides such that it would generate a family of secondary waves, resulting in significant modulation of the tidal amplitude (Mitchell et al., 1999; Beard et al., 1999). Such a modification in the tidal components would significantly affect the EEJ since it is driven essentially by the diurnal tide wind dynamo. In fact, in a recent study Vineeth et al. (2007a) have shown modulation of the tidal amplitudes in the electrojet region by the quasi 16-day wave during the SSW year (2005-2006). They also showed that when the phase of the quasi 16-day wave was positive, the tidal amplitudes were enhanced and when it was negative they got weakened. The CEJs were observed on all the days where tidal components were weakened and strong EEJs were observed when the amplitude of the tidal components strengthend. The effective weakening of the tidal components was seen to decrease with the damping of the wave. Though the strong modulations of the EEJ parameters were unequivocally demonstrated, proper association of the SSW with the occurrence of CEJ was not attempted in that study. The present study clearly shows that this association comes through the lower atmospheric circulation changes during SSW, which can facilitate easy upward prop- agation of planetary and gravity waves from stratospheric altitudes to lower thermosphere-ionosphere heights. In fact, it has already been shown earlier that the vertical wind associated with the upward propagating gravity waves in the dynamo region is very efficient in producing the CEJ over the dip equator (Raghavarao and Anandrao, 1980, 1987). In another study by Vineeth et al. (2007b), the gravity wave associated vertical wind has been discussed and shown to be causing CEJs simultaneously with the localized cooling at mesopause region. During the SSWs in this context, the role of vertical wind associated with the gravity waves would be of consequence in causing the CEJs, primarily in the phases when tidal amplitudes get weakened owing to the ongoing PW-tidal interactions. This inference is corroborated by our above mentioned earlier studies.

Typically, during the normal year, since the background wind over and near equatorial latitudes doesn't exhibit any significant change and therefore the upward propagating waves will be either filtered out in the lower atmosphere or not be sufficient enough to make strong modulation in the tides at mesospheric altitudes. This explains the non-occurrence of periodic CEJs during the normal winter months. The isolated/sporadic CEJ events of the normal years might be driven solely by the local wind changes e.g. through gravity waves in the electrojet region. However, it is difficult to separate out effect of local and global forcings in generating the CEJs. In this context, the new observations presented in the paper have significant implications as far as the high latitude low latitude coupling and its effects on dip equatorial region are concerned, especially in context of the causative mechanism of periodic CEJs.

\section{Conclusion}

The occurrence of CEJs of quasi 16-day period during "major mid winter Stratospheric Sudden Warming" events is presented. The results indicate the importance of wave forcing for the occurrence CEJ and the formation of high latitude SSW. The gravity wave-tidal interactions due to the enhanced PW activity as a result of the lower atmospheric circulation changes and subsequent modification in the tidal components are proposed to be the mechanisms for the strong modulations in the occurrence of CEJ.

Acknowledgements. This work was supported by Department of Space, Government of India. One of the authors C.Vineeth gratefully acknowledges the financial assistance provided by the Indian Space Research Organization through the research fellowship.

Topical Editor M. Pinnock thanks R. Stening and another anonymous referee for their help in evaluating this paper. 


\section{References}

Abdu, M. A., Ramkumar, T, K., Batista, I. S., Brum, C. G. M., Takahashi, H., Reinisch, B. W., and Sobral, J. H. A.: Planetary wave signatures in the equatorial atmosphere-ionosphere system, and mesosphere-E-and F-region coupling, J. Atmos.Sol. Terr. Phys., 68, 509-522, 2006.

Anandarao, B. G. and Raghavarao, R.: Structural changes in the currents and fields of the equatorial electrojet due to zonal and meridional winds, J. Geophys. Res., 92, 2514-2526, 1987.

Beard, A. G., Mitchell, N. J., Williams, P. J. S., and Kunitake, M.: Non-linear interactions between tides and planetary waves resulting in periodic tidal variability, J. Atmos. Solar Terr. Phys., 61, 363-376, 1999.

Chau, J. L., Fejer, B. G., Goncharenko, L. P.: Quiet variability of equatorial $\boldsymbol{E} \times \boldsymbol{B}$ drifts during a sudden stratospheric warming event, Geophys. Res. Lett., 36, L05101, doi:10.1029/2008GL036785, 2009.

Chen, P. R., Luo, Y., and Ma, J.: The QBO modulation of the occurrence of the Counter Electrojet, Geophys. Res. Lett., 22, 27172720, 1995.

Dunkerton, T., Hsu, C. P. F., and McIntyre, M. E.: Some Eulerian and Lagrangian diagnostics for a model stratospheric warming. J. Atmos. Sci., 38, 819-843,1981.

Dunkerton, T. J.: Theory of mesopause semiannual oscillation, J. Atmos. Sci., 39, 2681-2690, 1982.

Goncharenko, L. and Zhang, S. R.: Ionospheric signatures of sudden stratospheric warming: Ion temperature at middle latitude, Geophys. Res. Lett., 35, L21103, doi:10.1029/2008GL035684, 2008.

Gouin, P. and Mayaud, P. N.: A propos de existence possible d'un contre electrojet and latitudes magnetiques equatorials, Ann. Geophys., 23, 41-47, 1967.

Gurubaran, S.: The equatorial counter electrojet: Part of a worldwide current system?, Geophys. Res. Lett., 29(9), 1337, doi:10.1029/2001GL014519, 2002.

Hagan, M. E., Burrage, M. D., Forbes, J. M., Hackney, J., Randel, W. J., and Zhang, X.: QBO effects on the diurnal tide in the upper atmosphere, Earth Planets Space, 51, 571-578, 1999.

Hysell, D. L, Chau, J. L., and Fesen, C. G.: Effects of large horizontal winds on the equatorial electrojet, J. Geophys. Res., 107(A8), 1214, doi10.1029/2001JA000217, 2002.

Kalnay, E., Kanamitsu, M., Kistler, R., and Cillins, W.: The NCEP/NCAR 40-Year Reanalysis Project, B. Am. Meteorol. Soc., 77, 437-471, 1996.
Lindzen, R. S.: Turbulence and stress owing to gravity wave and tidal breakdown, J.Geophys.Res., 86(C10), 9707-9714, 1981.

Liu, H.-L. and Roble, R. G.: A study of a self-generated stratospheric sudden warming and its mesospheric - lower thermospheric impacts using the coupled TIME-GCM/CCM3, J. Geophys. Res., 107(D23), 4695, doi:10.1029/2001JD001533, 2002.

Mitchell, N. J., Middleton, H. R., Beard, A. G., Williams, P. J. S., and Muller, H. G.: The 16-day planetary wave in the mesosphere and lower thermosphere, Ann. Geophys., 17, 1447-1456, 1999, http://www.ann-geophys.net/17/1447/1999/.

Parish, H. F., Forbes, J. M., and Kamalabadi, F.: Planetary wave and solar oscillation in the equatorial electrojet, J. Geophys. Res., 99(A1), 355-368, 1994.

Raghavarao, R. and Anandarao, B. G.: Equatorial electrojet and the counter electrojet, Ind. J. Rad. Space. Phys., 16, 54-75, 1987.

Raghavarao, R. and Anandarao, B. G.: Vertical winds as a plausible cause for equatorial counter electrojet, Geophys. Res. Lett., 7, 357-360, 1980.

Randel, W. J., Garcia, R. R., and Wu, F.: Time dependent upwelling in the tropical lower stratosphere estimated from the zonal mean momentum budget, J. Atmos. Sci., 59, 2141-2152, 2002.

Rastogi, R. G., Rangarajan, G. G., and Somayajulu, V. V.: Complexities of the counter equatorial electrojet currents, Ind. J. Radio Space Phys., 21, 89-96, 1992.

Rastogi, R. G.: Lunar effects in the counter-electrojet near the magnetic equator, J. Atmos. Terr. Phys., 56, 167-170, 1974.

Somayajulu, V. V., Cherian, L., Rajeev, K., Ramkumar, G., and Reddi, C. R.: Mean wind and tidal components during counter electrojet events, Geophys. Res. Lett., 20, 1443-1446, 1993.

Stening, R. J., Meek, C. E., and Manson, A. H.: Upper atmosphere wind systems during reverse equatorial electrojet events, Geophys. Res. Lett., 23, 3243-3246, 1996.

Stening, R. J., Forbes, J. M., Hagan, M. E., and Richmond, A. D.: Experiments with lunar atmospheric tidal model, J. Geophys. Res., 102, 13465-13471, 1997.

Vineeth, C., Pant, T. K., Devasia, C. V., and Sridharan, R.: Atmosphere- Ionosphere coupling observed over the dip equatorial MLTI region through the quasi 16-day wave, Geophys. Res. Lett., 34, L12102, doi:10.1029/2007GL030010, 2007a.

Vineeth, C., Pant, T. K., Devasia, C. V., and Sridharan, R.: Highly localized cooling in daytime mesopause temperature over the dip equator during counter electrojet events: First results, Geophys. Res. Lett., 34, L14101, doi:10.1029/2007GL030298, 2007 b. 